\title{
EL CASO QUINTERO-PUCHUNCAVÍ Y LA EFICACIA DE LA ACCIÓN DE PROTECCIÓN COMO MECANISMO INSTITUCIONAL DE SOLUCIÓN DE CONFLICTOS SOCIOAMBIENTALES
}

\author{
THE QUINTERO-PUCHUNCAVÍ CASE AND THE \\ EFFECTIVENESS OF THE CONSTITUTIONAL \\ REMEDY AS AN INSTITUTIONAL MECHANISM OF \\ SOCIO-ENVIRONMENTAL CONFLICTS RESOLUTION
}

\begin{tabular}{|c|c|}
\hline \multicolumn{2}{|c|}{ COMENTARIO DE JURISPRUDENCIA } \\
\hline CóMO CITAR ESTE ARTíCulo (CHICAGO) & 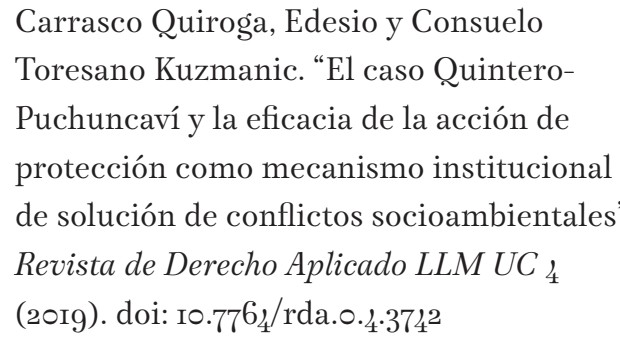 \\
\hline \multirow[t]{2}{*}{ REVISTA DE DERECHO APLICADO LLM UC } & $\begin{array}{l}\text { Número } 4 \\
\text { Diciembre } 2019 \\
\text { ISSN: } 245^{2-4344}\end{array}$ \\
\hline & $\begin{array}{l}\text { Recepción: } 30 \text { de octubre, } 2019 \\
\text { Aceptación: I7 de diciembre, } 2019\end{array}$ \\
\hline
\end{tabular}




\section{Resumen}

El objeto del presente trabajo es analizar la sentencia adoptada por la Corte Suprema ante la interposición de varios recursos de protección en contra de la Administración del Estado y las empresas que operan en el sector de Quintero y Puchuncaví, debido a la grave contaminación que allí se extiende. Se examinan las consecuencias institucionales que se derivan de la utilización del recurso de protección como mecanismo de control de la Administración del Estado por parte de la Corte Suprema en materia normativa, generando, entre otras cosas, una alteración a la naturaleza cautelar del recurso como mecanismo para resolver este tipo de disputas.

Palabras clave: Recurso de protección, derechos fundamentales, control, derecho ambiental.

\section{Abstract}

The purpose of this paper is to analyze the Supreme Court's opinion on the remedy filed against the Government and companies operating in the Quintero-Puchuncaví bay, aimed at protecting constitutional rights being breached due to the serious pollution affecting the area. The paper further examines the institutional implications of the use, by the Supreme Court, of the constitutional remedy as a governmental control mechanism, such as the alteration of the precautionary nature of the constitutional remedy.

Keywords: Constitutional remedy, fundamental rights, interference, control, environmental law. 


\section{Edesio Carrasco Quiroga}

Pontificia Universidad

Católica de Chile

Santiago, Chile

ecarrasc@uc.cl

Pontificia Universidad

Católica de Chile

Santiago, Chile

ecarrasc@uc.cl
Edesio Carrasco Quiroga es abogado de la Pontificia Universidad Católica de Chile y Máster en Derecho (LLM) con mención en Derecho Ambiental de la Universidad de California, Berkeley, Estados Unidos. Es profesor del Magíster LLM UC, mención Derecho Regulatorio. Fue director Regional, jefe de la Unidad de Litigios y fiscal del Servicio de Evaluación Ambiental. Actualmente es socio de Schultz, Carrasco \& Benítez Abogados.

Edesio Carrasco Quiroga is a lawyer from the Pontificia Universidad Católica de Chile and master's in law (LLM) with a mention in Environmental Law from the University of California, Berkeley, United States. He is a Regulatory Law professor at the LLM UC. He was Regional Director, head of the Litigation Unit and prosecutor of the Servicio de Evaluación Ambiental in Chile. He is currently a partner of Schultz, Carrasco \& Benítez Abogados.

\section{Consuelo Toresano Kuzmanic}

Schultz, Carrasco \&

Benítez Abogados

Santiago, Chile

ctoresano@scyb.cl

Schultz, Carrasco \&

Benítez Abogados

Santiago, Chile

ctoresano@scyb.cl
Consuelo Toresano Kuzmanic es abogado de la Pontificia Universidad Católica de Chile y ayudante de Derecho Administrativo en la misma universidad, donde también cursó el Diplomado en Derecho Administrativo. Es miembro del Área de Derecho Público y Derecho Corporativo de Schultz, Carrasco \& Benítez Abogados.

Consuelo Toresano Kuzmanic is a lawyer of the Pontificia Universidad Católica de Chile and an assistant of Administrative Law at the same university, where she took the Diploma in Administrative Law. She is a member of the Public Law and Corporate Law Area of Schultz, Carrasco \& Benítez Abogados. 


\section{INTRODUCCIÓN}

La contaminación en la zona de Quintero y Puchuncaví es grave. Se extiende por décadas y el Estado ha estado lejos de dar una solución institucional a los vecinos que por años han sufrido sus efectos. Se trata de una situación injusta que debe corregirse, pero cuyos mecanismos de solución jurídica no son nítidos. El Estado ha permitido el desarrollo de una zona industrial en el área, llevándola a límites que requieren hoy una solución distinta a la de décadas anteriores, considerando el contexto en el que el Estado Chile y el derecho internacional conciben hoy la protección del medioambiente.

De esta forma, el objeto de este trabajo es analizar la sentencia adoptada por la Corte Suprema el 28 de mayo de este año ${ }^{1}$, a partir de la interposición de varios recursos de protección en contra de órganos de la Administración del Estado y las empresas que en dicho sector operan, la que estableció, en síntesis, diversas medidas a ejecutar en el plazo de un año con el objeto de restablecer el imperio del derecho en la zona de Quintero y Puchuncaví. A lo anterior, se suma una segunda sentencia de la Corte Suprema, esta vez en materia de daño ambiental, la que también contribuye a explicar este fenómeno²: aquel en que los tribunales de justicia terminan definiendo lo que en esa área debe hacerse para solucionar un problema de contaminación ambiental.

En esos términos, el presente trabajo analiza la solución otorgada por la Corte Suprema para este caso. Así, se explica cómo, ante la falta de soluciones institucionales, fue la Corte Suprema la que terminó resolviendo en forma parcial el problema de justicia ambiental de dicha zona, a partir de una acción cautelar y de emergencia, no diseñada, en principio, para este tipo de situaciones. Asimismo, se examina el riesgo institucional de solucionar problemas de esta naturaleza a partir de la interposición y resolución de este tipo de acciones.

Para ello, este trabajo sintetiza el caso y la sentencia, y expone las consecuencias que, desde el punto de vista institucional - sobre todo ambiental-, una sentencia como esta conlleva.

\section{SÍNTESIS DEL CASO Y LA SENTENCIA}

El 28 de mayo de 2019, la Corte Suprema ordenó un conjunto de medidas al Estado en uno de los casos más emblemáticos ocurridos en la bahía de Quintero y Puchuncaví, en

1 Francisco Chahuán Chahuán con Empresa Nacional de Petróleos, ENAP S.A., Corte Suprema, rol 5888-20I9, 28 de mayo de 20 I9.

2 Municipalidad de Quintero con ENAP Refinería S.A. y Remolcadores Ultratug Limitada, Corte Suprema, rol I3.I77-20I8, 25 de septiembre de 2019 . 
la región de Valparaíso. En este fallo, la Corte Suprema reconoció la vulneración de un conjunto de derechos fundamentales, como la vida, la salud y el derecho a vivir en un medioambiente libre de contaminación; además, estableció la responsabilidad del Estado por su inacción ordenando quince medidas para reparar, en parte, la situación de injustica ambiental que la zona viene sufriendo desde hace décadas.

En efecto, la Municipalidad de Quintero, ciertos órganos de la Administración del Estado, un conjunto de habitantes de la zona y organizaciones de la sociedad civil (ONG), interpusieron diversos recursos de protección ante la Corte de Apelaciones de Valparaíso invocando la vulneración de los derechos antes indicados, en razón de verse afectados por náuseas, vómitos, mareos e incluso desvanecimientos después de inhalar gases que producían un olor nauseabundo en la zona de Quintero y Puchuncaví. Dichos gases habrían sido emitidos por las empresas que operan en la zona desde hace décadas por medio de diversas industrias contaminantes, como una central termoeléctrica, una fundición de cobre, un terminal gasífero, una refinería, una planta productora de cemento, etcétera, las que constituyen, entre todas, un complejo industrial intenso en fuentes emisoras de gases.

Así, la acción fue dirigida en contra de las empresas por la generación de los gases y compuestos químicos que habrían producido la alerta indicada; además de en contra de órganos de la Administración del Estado como los ministerios del Medio Ambiente, de Salud y del Interior, la Superintendencia del Medio Ambiente y la intendencia regional. Esto incluye, dentro de los recurridos, incluso al presidente de la República, por los incumplimientos en que estos distintos organismos habrían incurrido al no adoptar medidas de prevención, deberes de control y de sistematización de la información, así como de fiscalización y represión de conductas ilícitas, reprochándoles, junto a ello, el no haber actuado de manera coordinada.

\section{I. La sentencia}

Luego de haber sido rechazado el recurso en primera instancia por la Corte de Apelaciones de Valparaíso ${ }^{3}$, la Corte Suprema revocó el fallo, acogiendo parte de las acciones interpuestas y ordenando una serie de medidas y acciones concretas que diversos organismos estatales deben ejecutar.

En ese sentido, un primer elemento sustantivo del fallo dice relación con el agrupamiento que la sentencia hace de las garantías constitucionales invocadas, al indicar que debe analizarse su vulneración en conjunto, "puesto que una afectación seria de la salud, por causa de una emergencia ambiental severa, amenaza también la vida y, en todo caso, la integridad física o, cuando menos, psíquica, de las personas" (considerando 15), califican-

3 Francisco Chahuán Chahuán con Empresa Nacional de Petróleos, ENAP S.A., Corte de Apelaciones de Valparaíso, rol 7266-20I9, Ig de febrero de 2019. 
do la emergencia bajo una naturaleza ambiental y sanitaria, por lo que ambos derechos (derecho a la vida y el derecho a vivir en un medioambiente de libre de contaminación) pueden confluir en el caso de que se quiera adoptar una medida cautelar al respecto.

En términos materiales, atribuye una serie ilegalidades a diferentes organismos estatales exigiéndoles acciones activas en el cumplimiento de ese deber. Así, señala que, para comenzar a concretar medidas, el Ministerio del Medio Ambiente solo reaccionó una vez que ya habían ocurrido nuevos sucesos de contaminación, sin explicar de qué modo habrían servido acciones concretas para prevenirla.

De la misma manera, señala que el Ministerio de Salud había hecho labores "insuficientes" en relación con la gravedad de la situación, al no haber asumido un rol proactivo, pues, en lugar de implementar medidas preventivas, reaccionó solo con posterioridad a los sucesos de intoxicación.

Por último, la Corte Suprema también estima que la actuación de la Oficina Nacional de Emergencia (Onemi) es ilegal, al no adoptar "previamente los planes de emergencia o de contingencia específicos y necesarios para enfrentar la situación de que se trata, limitándose a reaccionar, como los demás recurridos, ante los eventos en cuestión" (considerando 30), imputándole, además, responsabilidad al Ministerio de Interior al no haber verificado de forma adecuada, en un servicio de su dependencia funcional, que se hubiesen concretado las diversas diligencias e intervenciones una vez ocurrida la catástrofe de que se trata.

Son estas infracciones las que, a juicio de la Corte Suprema, han impuesto una fuente de contaminación para el entorno de esas comunas, lo que generó los episodios de contaminación de los días 21 y 23 de agosto y 4 de septiembre de 2018, lo que constituye una clara transgresión al concepto de desarrollo sustentable, "reconocido por el derecho interno y los tratados internacionales" (considerando 35), pese a lo difícil que ha sido, luego de nueve meses de transcurridos los hechos, determinar fehacientemente quiénes los produjeron, lo cual se señala en el considerando 26. Por eso, según sentenció el tribunal, ello constituiría una amenaza concreta, cierta y que no puede ser ignorada para la integridad, salud y vida de los vecinos de Quintero, Ventanas y Puchuncaví, así como para el medioambiente en que habitan.

En esos términos, la sentencia recurre a los principios precautorio y preventivo para definir las medidas que corresponde aplicar, invocando una serie de otros principios también vinculados que son recogidos en la Declaración de la Cumbre Judicial Iberoamericana del Poder Judicial de la República de Chile, denominada "Principios jurídicos medioambientales para un desarrollo ecológicamente sustentable" ", la que pareciera influye en buena parte de la sentencia al momento de dictarla.

4 "Principios jurídicos medioambientales para un desarrollo ecológicamente sustentable", Cumbre Judicial Iberoamericana, http://www.cumbrejudicial.org/images/imagenes/Principios_Jur\% C3\%ADdicos_Medioambientales_para_un_Desarrollo_Ecol\% 3 C $\%$ B3gicamente Sustentable.pdf. 
Por todo lo anterior, la sentencia ordena, en síntesis y en sus mandatos relevantes:

- Que la autoridad ambiental efectúe, a la brevedad, los estudios pertinentes para establecer el método más idóneo y adecuado para identificar, determinar la naturaleza y características precisas de los gases, elementos o compuestos producidos por todas y cada una de las fuentes presentes en la bahía de Quintero, Ventanas y Puchuncaví.

- Que una vez evacuado el estudio aludido, la autoridad administrativa deberá disponer en breve plazo lo pertinente para implementar las acciones que se desprendan de dicho informe, en el que se habrá debido evaluar la procedencia de instalar filtros o dispositivos que permitan identificar y medir esos compuestos o elementos directamente en la fuente, entre otros aspectos.

- Que el Ejecutivo disponga lo adecuado para que las medidas que surjan del informe aludido estén cabalmente implementadas y, además, en disposición de comenzar a operar, en el término máximo de un año contado desde el día en que esta sentencia se encuentre firme.

- Que una vez ejecutadas las acciones sugeridas en ese estudio, esto es, recopilada la información idónea y pertinente, las autoridades sectoriales deberán llevar a cabo las actuaciones apropiadas para determinar, a la brevedad y con precisión, la identidad de todos y cada uno de los elementos o compuestos dañinos para la salud y para el medioambiente generados por las distintas fuentes existentes en la bahía de Quintero, Ventanas y Puchuncaví, estableciendo con detalle cuáles son sus características y demás aspectos.

- Establecido lo anterior, la sentencia dispone que las instalaciones y fuentes que generen estos elementos deberán reducir sus emisiones a las cifras que para cada uno de ellos establecerán las autoridades administrativas competentes, quienes a la brevedad fijarán los parámetros que deberán comenzar a regir, a su turno, en un plazo acotado y preciso que se establecerá por la autoridad administrativa.

- Asimismo, el tribunal solicita que se inicien a la brevedad los procedimientos pertinentes para ponderar la pertinencia y utilidad de reformar, incrementando, incluso, si fuere necesario, los niveles de exigencia aplicables a los distintos elementos, gases o compuestos producidos en las diferentes fuentes presentes en la bahía de Quintero, Ventanas y Puchuncaví, las normas de emisión, de calidad ambiental y demás que resulten aplicables a la situación de contaminación de la bahía. 
- Una vez identificados y cuantificados los elementos nocivos para la salud y para el medioambiente, el fallo requiere a la autoridad de salud adoptar las medidas pertinentes, útiles y necesarias para resguardar la salud de la población afectada por la contaminación existente en las comunas de Quintero y Puchuncaví, las cuales se señalan en la sentencia. Asimismo, se deberán diseñar e implementar una política destinada a enfrentar situaciones de contingencia como las que generaron la causa, a fin de dar satisfacción al importante aumento en la demanda de atenciones de salud. Del mismo modo, la autoridad deberá disponer lo que fuere preciso para acometer la derivación de aquellos pacientes que, en episodios como los de la especie, requieran de tal medida de cuidado y atención.

- Que la Oficina Nacional de Emergencia proceda, a la brevedad, a elaborar un Plan de Emergencia que permita enfrentar situaciones de contaminación como las ocurridas, instrumento en el que deberá incorporar, además, todas las medidas de coordinación, de disposición de recursos y las demás que se estimen atinentes y útiles para solucionar los problemas derivados de esos eventos.

- Que cada vez que se constate la existencia de niveles de contaminación que afecten en particular a niños, niñas y adolescentes, según lo precisado por la autoridad administrativa o por los efectos que produzcan en tal población y que se expresen en una sintomatología de su estado de salud, condición que del mismo modo precisará la autoridad administrativa de salud y educación, las magistraturas competentes dispondrán, según ordena la sentencia, lo pertinente para trasladar desde la zona afectada por esa situación a todas las personas que integran el señalado conjunto hacia lugares seguros, medida que se deberá mantener hasta que cese el evento de crisis.

- El resto de la población vulnerable de Quintero, Ventanas y Puchuncaví, cada vez que se produzca un evento crítico de contaminación, será trasladada desde la zona afectada hacia lugares seguros mientras perdure el episodio.

- Que se reevalúe la calificación de zona de latencia y de zona saturada de las comunas de que se trata, análisis a partir del cual la autoridad competente deberá adoptar las medidas que corresponda.

- Que se cree y mantenga un sitio web en el que se incorporarán todos los datos, antecedentes, pesquisas, resultados, informes, etcétera, que den cuenta de las distintas actuaciones llevadas a cabo con el objeto de dar cumplimiento a las medidas dispuestas en la sentencia, utilizando, en la medida de lo posible, un lenguaje claro que simplifique la comprensión de los asuntos abordados. 
- Que, si con ocasión de la ejecución de las tareas previstas en el fallo, las autoridades recurridas detectan la concurrencia de situaciones que justifiquen la aplicación de sus atribuciones, como podría ser alguno de los supuestos previstos en el artículo 25 quinquies de la Ley 19.300, den inicio a los cursos de acción pertinentes para hacer efectivas estas potestades, evaluación en la que habrán de tener en especial consideración los efectos sinérgicos que las distintas fuentes contaminantes puedan producir en el medioambiente de Quintero, Ventanas y Puchuncaví.

- La Secretaría Regional Ministerial de Vivienda y Urbanismo deberá abordar la modificación del Plan Regulador de Valparaíso, en relación con la zona afectada por los hechos de autos, a la brevedad, considerando dicha labor como una prioridad en sus políticas sectoriales, sin perjuicio de cualquier otra diligencia o actuación necesaria para dar cabal cumplimiento a lo ordenado.

\section{COMENTARIO}

Revisada la sentencia, hace sentido comentar diversos aspectos, tanto desde una perspectiva procedimental como orgánica y sustantiva, toda vez que muchas de las medidas que la sentencia ordena tienen efectos institucionales en esas tres dimensiones. En ese sentido a propósito de esta sentencia, Luis Cordero ${ }^{5}$ ha indicado que, en el derecho administrativo, pero especialmente en este caso, el contexto cumple un rol relevante y por lo tanto el fallo debe entenderse bajo un "profundo rol simbólico", cumpliendo también la sentencia un rol pedagógico al indicar a la comunidad "en qué casos sus derechos pueden ser tutelados".

En una perspectiva más crítica respecto del fallo se ha referido Alejandro Silva ${ }^{6}$, quien ha indicado que los jueces "instrumentalizaron su oficio para hacer justicia más allá de los límites constitucionales". Para Silva, la Corte se habría impacientado con la política erigiéndose en "una superautoridad en la línea de mando de la Administración del Estado, disponiendo todo lo que las autoridades deben hacer, cómo deben hacerlo y cuándo deben hacerlo. En otras palabras, se transformó en Ejecutivo", remarca.

Al margen de las críticas o análisis de esta sentencia, lo concreto es que este fallo refleja lo complejo que es resolver una contienda de naturaleza ambiental y administrativa, que pone a los jueces en el centro de la atención, ya que son ellos, en un derecho escasamente codificado, los llamados a delimitar los contornos de las potestades y reglas aplicables.

5 Luis Cordero Vega, "Un aparente activismo", La Tercera, I de junio de 20r9, https://www. latercera.com/opinion/noticia/un-aparente-activismo/680022/.

6 Luis Alejandro Silva Irarrázaval, “Jueces y política”, La Tercera, I de junio de 2org, https:// www.latercera.com/opinion/noticia/jueces-y-politica-4/68005I/. 
En este caso particular estamos, además, en presencia de una situación de alto impacto mediático, en la que se exceden las consideraciones meramente jurídicas y en la cual las apreciaciones sobre el mérito de una acción $u$ omisión de una autoridad política son frecuentes, dado que el caso Puchuncaví y Quintero simboliza buena parte de los conflictos socioambientales que se han judicializado en la última década.

Considerando lo anterior, se abordan a continuación cinco aspectos que merecen atención desde el punto de vista institucional, con sus respectivas ideas matrices.

\section{I. Estamos en presencia de una nueva forma en que la Corte Suprema comprende la acción de protección en materia ambiental}

Un primer aspecto para comentar del fallo dice relación con la forma en que la Corte Suprema aborda un problema que, en principio, se refería a incumplimientos ambientales en que diversas compañías habían incurrido. No obstante, al resolverse el asunto y "reestablecer el imperio del derecho", la sentencia termina definiendo lo que la regulación y la política ambiental deben ejecutar, pese a no definir quiénes (de las empresas) estaban incumpliendo la legislación o sus autorizaciones de funcionamiento.

De esta manera, esta sentencia no trata sobre aspectos que tradicionalmente esta acción había comprendido en materia ambiental, como la evaluación y la fiscalización de actividades y proyectos, sino que se adentra en la forma en que diversos órganos de la Administración del Estado deben cumplir sus competencias en un área determinada frente a un conflicto particular y concreto.

Por eso, esta sentencia abre una nueva forma de comprender esta acción constitucional, desplazando la frontera en que la acción de protección se había desarrollado ${ }^{7}$, yendo más allá del control de la legalidad de los comunes instrumentos de gestión que la Ley 19.300 dispone.

En esos términos, la forma en que resuelve la Corte Suprema, más allá de restablecer el imperio del derecho de manera urgente ante la privación, perturbación o amenaza en el ejercicio legítimo de un derecho - como se verá en el acápite siguiente-, termina adoptando una posición de tutela judicial objetiva, en la que los ciudadanos pueden exigir la aplicación de la legislación administrativa relativa a intereses colectivos (citizen enforecement). En términos prácticos, lo que la sentencia pareciera dar vida es a una especie de

$7 \quad$ Para efectos de revisar la evolución que esta acción ha tenido en el tiempo en cuanto a sus tendencias, puede revisarse Edesio Carrasco Quiroga, "De Trillium a Central Los Cóndores:

Continuidad y cambio del recurso de protección ambiental en veinte años de jurisprudencia”. Revista de Justicia Ambiental 9: 275-298. 
citizen suits impropia, en la que ante los casos de inactividad administrativa ambiental se "pueda exigir directamente frente a los infractores (ya sean particulares o entes públicos) la aplicación de la legislación administrativa ambiental pudiendo utilizar, entre otras, pretensiones de condena (injuctions), y sin que se puedan pedir indemnizaciones por daños y perjuicios individuales (damages), porque no se trata de resarcir daños o lesiones individuales sino colectivas" ${ }^{8}$.

Al margen de las diferencias que nuestro derecho tiene con el derecho anglosajón, lo cierto es que la sentencia adopta un control objetivo de la legalidad, al tutelar un interés público o colectivo, y advertir que el monopolio del interés público radica no solo en la Administración del Estado, sino también en los tribunales de justicia.

Así, la sentencia se aparta de un criterio subjetivo de control de la legalidad al momento de evaluar una determinada afectación a un derecho constitucional, sobrepasando las lógicas del interés directo o indirecto de un reclamante y adoptando un rol activo ante infracciones al derecho objetivo de carácter ambiental, asumiendo con energía una discreción que, en principio, radica en la función ejecutiva de la Administración del Estado.

Si bien es prematuro concluir que la acción de protección seguirá esta lógica ante situaciones de similares características, lo cierto es que constituye una aproximación novedosa y finalista, en la que a partir del control de la legalidad objetiva y la protección de derechos (en general), los tribunales de justicia abordan materias de interés público, como ya lo han hecho en empleo público y salud ${ }^{9}$, sin soslayar las tensiones institucionales que una postura como esta también genera.

\subsection{Se ha alterado el carácter cautelar o la naturaleza de esta acción constitucional}

El objeto de esta acción constitucional es el restablecimiento del imperio del derecho y la obtención de la debida protección frente a la vulneración de las garantías fundamentales establecidas en el artículo 20 de nuestra Constitución. Se trata, además, de una acción de carácter urgente y cautelar por medio de la cual se busca restablecer el Estado de derecho, toda vez que la acción de protección permite solicitar la adopción inmediata de las providencias que se juzguen necesarias por parte del tribunal.

8 Alexander Peñalver i Cabré, La defensa de los intereses colectivos en el contencioso-administrativo (Madrid: Thomson Reuters Aranzadi, 20I6), I58.

Para una revisión de una discusión reciente en materia de salud, véase, por ejemplo, la entrevista a la ministra de la Corte Suprema, Ángela Vivanco Martínez, quien expone una posición similar, en que la Corte Suprema ha obligado al Estado de Chile a financiar medicamentos de alto costo, pese a existir una ley que regula el sentido y alcance de esta prestación. I. Toro y P. Toro, "Ángela Vivanco, ministra Corte Suprema: 'No puede ser que el mensaje sea que por falta de recursos usted deba morirse", La Tercera, 5 de octubre de 2019 , https://www.latercera.com/nacional/noticia/angela-vivanco-ministra-corte-suprema-no-puede-mensaje-sea-falta-recursos-usted-deba-morirse $/ 8,89,66 /$. 
El hecho de que la acción de protección pueda calificarse como un procedimiento "de urgencia” se desprende características como su informalidad, su carácter breve y concentrado, y el que sea un procedimiento inquisitivo.

Por su parte, la Corte Suprema se ha referido varias veces a la naturaleza cautelar y de urgencia de esta acción, señalando que es una "acción de naturaleza cautelar, urgente, destinada a resguardar los derechos fundamentales a que ella se refiere" ${ }^{10}$, y ha reafirmado al señalar que "la presente vía constituye una acción de cautela de derechos fundamentales, pues busca dar amparo judicial efectivo y oportuno a quienes ven vulneradas sus garantías constitucionales producto de actos $\mathrm{u}$ omisiones ilegales $\mathrm{y} / \mathrm{o}$ arbitrarias" ${ }^{11}$.

En este caso particular, creemos que se ve alterada la naturaleza esencialmente cautelar de esta acción en su parte resolutiva. En efecto, al acoger los recursos de protección interpuestos, la sentencia ordena a las autoridades declaradas responsables, la implementación de quince medidas tendientes a, entre otras cosas, identificar los contaminantes, sus fuentes, informar a la población y adoptar acciones para hacer cesar dicha contaminación. Para ello, fija un plazo máximo de un año e incluso, en la mayoría de las medidas, ni siquiera se señala un plazo para su implementación, limitándose a señalar que estas deben ejecutarse "a la brevedad".

De esta manera, pese a que la Corte Suprema reconoce en la sentencia la grave vulneración de derechos que afecta a los vecinos de la localidad de Quintero y Puchuncaví, no genera el restablecimiento inmediato del imperio del derecho ni cautela con urgencia las garantías vulneradas toda vez que, durante su período de implementación -que se interpreta debe ser de un año máximo, mientras que es incierto en qué plazo espera la Corte que se implementen soluciones cuando señala que debe hacerse "a la brevedad"-, se mantendría el statu quo, continuando la ilegalidad objetiva denunciada y la vulneración de derechos. Así, el restablecimiento del imperio del derecho no se efectuaría hasta que dichas medidas se hayan implementado en su totalidad.

En otras palabras, por medio del fallo se establece la responsabilidad que ciertos órganos de la Administración del Estado tendrían en materia de protección ambiental, pero no se adopta ninguna medida cautelar o urgente en relación con las garantías que se indica que se vulneran, con lo cual, se altera la naturaleza de la acción de protección, tal como, al menos, la norma constitucional y la jurisprudencia la han entendido.

10 Caso María Mónica Avilés González con Director General de Carabineros, Gustavo Adolfo González Jure, Corte Suprema, rol 2536-2013, 27 de junio de 2013.

11 Caso Confederación Nacional de Funcionarios con Tribunal Constitucional, Corte Suprema, rol 21027-2019, 7 de octubre de 2019 . 
Lo anterior se ve reflejado en el voto de prevención del ministro Aránguiz, el cual señala que una actuación "conforme al prisma cautelar" implicaría, como de hecho lo propone, que la Corte Suprema hubiese suspendido por un plazo de 90 días toda actividad de las empresas públicas y privadas que operan en el Complejo Industrial Ventanas, a fin de que, dentro de dicho plazo, ellas presenten un programa de prevención y descontaminación para la bahía de Quintero, Ventanas y Puchuncaví.

En efecto, dicha suspensión, según indica el ministro Aránguiz, permitiría "que confluyan los factores que pueden aportar a tal resultado", toda vez que, a pesar de no existir conocimiento respecto de su origen y autor, "no hay otras fuentes de contaminación posibles". Más allá del análisis de proporcionalidad de la medida que propone el ministro Aránguiz, lo cierto es que su análisis sobre el carácter urgente y cautelar de esta acción es correcto, al concebirla como un mecanismo o remedio urgente, ante la privación, perturbación o amenaza concreta al ejercicio de ciertos derechos, y hace una interpretación adecuada, al menos en la teoría, respecto de las particularidades de esta acción, lo que demuestra que, para superar lo que ocurre en Quintero y Puchuncaví, hay mecanismos más eficientes y precisos que los utilizados ${ }^{12}$.

\section{3·3. Importancia de la información ambiental}

Además de lo ya señalado, es importante destacar la relevancia que le da esta sentencia a la información en el contexto de la protección ambiental. En efecto, muchas de las medidas ordenadas están vinculadas a la necesidad de recopilar, sistematizar y difundir información. En esa línea, se ordena hacer informes que identifiquen las fuentes de contaminación y que se implementen acciones en contra de esta, así como crear y mantener un sitio web para facilitar el acceso a dicha información a las personas interesadas.

La misma lógica se siguió en una sentencia reciente de la Corte Suprema, en la cual se condenó a la empresa ENAP Refinerías a adoptar una serie de medidas tendientes a reparar el daño ambiental causado a la bahía de Quintero. Así, ENAP tendrá que recopilar información para analizar los riesgos de la actividad de descarga de combustibles, así como implementar programas de monitoreo, por lo que debe informar en forma bimensual al Ministerio del Medio Ambiente respecto de los resultados de las medidas implementadas. De esta forma, la Corte Suprema destaca la importancia de la comunicación e intercambio de información entre esta empresa privada y las autoridades competentes como un valor esencial en la protección del medioambiente.

Para una crítica de la sentencia en la que se destaca la prevención del ministro Aránguiz, véase Marie Claude Plumer Bodin y Rocío Parra Cortés, "Fallo de la Corte Suprema por Quintero-Puchuncaví: Algo más que una victoria pírrica”, El Mostrador, I de junio de 2org, https://www.elmostrador.cl/noticias/opinion/columnas/20Ig/o6/or/fallo-de-la-corte-suprema-por-quintero-puchuncavi-algo-mas-que-una-victoria-pirrica/. 
La importancia de la información en materia de protección ambiental también se ha dado a nivel regional e internacional. En efecto, el Acuerdo de Escazú tiene como uno de sus pilares fundamentales el garantizar el derecho de todas las personas a tener acceso a la información de manera oportuna y adecuada, a participar de manera significativa en las decisiones que afectan sus vidas y su entorno y a acceder a la justicia cuando estos derechos hayan sido vulnerados. Es más, en el propio nombre del Acuerdo se establece que trata sobre "el acceso a la información [...] en asuntos ambientales". En esa línea, la transparencia, la apertura y la participación son principios que en el Acuerdo se consagran.

De la misma manera, a nivel internacional existe el Convenio de Aarhus, el cual también tiene por objeto regular los derechos de acceso a la información, participación ciudadana y acceso a la justicia en relación con el medioambiente. De esta manera, es posible ver la importancia global que se da a la información sobre la protección del medioambiente, aplicando el décimo principio de la Convención de Río, que justamente establece la necesidad de que las autoridades garanticen el acceso a la información en estos temas.

Sin embargo, esta importancia otorgada al acceso a la información no ha sido considerada de la misma manera por el Tribunal Constitucional. En efecto, en una sentencia reciente ${ }^{13}$, el Tribunal acogió una acción de inaplicabilidad por inconstitucionalidad de los artículos 5 inciso segundo y 10 inciso segundo de la Ley sobre Acceso a la Información Pública, así como del artículo 31 bis de la Ley sobre Bases Generales del Medio Ambiente, señalando que dichos preceptos, referidos a la información ambiental —en especial el último-, superan en amplitud al artículo 8 inciso segundo de la Constitución Política de la República, el cual no permite hacer pública toda la información que produzca o esté en poder de la Administración, sino que solo a la información contenida en los "actos", "resoluciones", "fundamentos" y "procedimientos”. Así, una solicitud para acceder a información sobre uso de antibióticos por salmoneras debía ser rechazada, toda vez que lo dispuesto en el artículo 8 inciso segundo de la Constitución Política de la República no permitiría el acceso a dicha información. Dicho criterio ya había sido adoptado por el Tribunal Constitucional en el pasado, en una causa muy similar ${ }^{14}$.

El razonamiento del Tribunal se basa en que los preceptos contenidos en la Ley 20.285 disponen que es pública "la información elaborada con presupuesto público y toda otra información que obre en poder de los órganos de la Administración”. Similar a ello, el artículo 31 bis de la Ley 19.300 establece que "toda persona tiene derecho a acceder a la información de carácter ambiental que se encuentre en poder de la Administración, de conformidad a lo señalado en la Constitución Política de la República y en la Ley 20.285 sobre Acceso a la Información Pública”. La norma añade que, en general, debe entenderse

\footnotetext{
13 Sentencia del Tribunal Constitucional, rol 4986-I8, I4 de mayo de 2019 .

14 Sentencia del Tribunal Constitucional, rol 2907-I5, 27 de diciembre de $20 \mathrm{I} 6$.
} 
por información ambiental toda aquella que verse sobre el medioambiente. Esto incluye, entre otros elementos ambientales, el aire, la atmósfera, el agua, el suelo, los paisajes o la diversidad biológica. De igual forma, incluye los factores que afecten o amenacen dichos elementos, como sustancias, energía, residuos o emisiones.

Sin embargo, el artículo 8 de la Constitución dispone en lo pertinente que "son públicos los actos y resoluciones de los órganos del Estado, así como sus fundamentos y los procedimientos que utilicen" ${ }^{15}$, con lo que restringe parte del acceso a la información que los propios particulares han puesto en poder de la Administración del Estado, y sirve como base para la conclusión del Tribunal Constitucional, en cuanto a que las normas de la Ley 20.385 y la Ley 19.300 superan en amplitud al artículo 8 de la Constitución, por lo que requerimientos de información que también superen la amplitud de dicho artículo deben ser rechazados.

Lo antes expuesto refleja que el acceso a la información en materia ambiental es otro factor de tensión institucional, en este caso, entre el Tribunal Constitucional y la Corte Suprema, influido también por la discusión respecto del Convenio de Escazú en Chile, ya que no existe claridad respecto de si dicho acceso debe ser absoluto o si admite limitaciones ${ }^{16}$. De esta manera, este fallo refleja que la información ambiental es relevante en el marco del acceso a la justicia ambiental, pero también nos recuerda el propio Tribunal Constitucional que el acceso a la información ambiental no es a cualquier precio, y que hay reglas constitucionales que limitan el ejercicio de este derecho.

\subsection{Interferencia de la separación de funciones}

Sin perjuicio de las consideraciones expuestas, de las medidas que la sentencia exige también se advierte una interferencia con las funciones que la Presidencia de la República tiene en el ámbito de sus competencias. En efecto, dentro de las medidas requeridas está el iniciar "a la brevedad" un procedimiento para "ponderar la pertinencia y utilidad de reformar, incrementando, incluso, si fuere necesario, los niveles de exigencia aplicables a los distintos elementos, gases o compuestos producidos en las diferentes fuentes presentes en la bahía de Quintero, Ventanas y Puchuncaví, las normas de emisión, de calidad

15 Verónica Marín y Fernanda Villalobos, “Tratado de Escazú: La polémica en torno a sus beneficios y eventuales trabas a la inversión”, Emol, 3 de octubre de 20I8, https://www.emol.com/ noticias/Nacional/2018/10/o3/g227II/Tratado-de-Escazu-La-polemica-en-torno-a-sus-beneficios-y-eventuales-trabas-a-la-inversion.html.

16 Esta discusión fue resuelta recientemente por la Corte Suprema, en una sentencia en la cual se pronunció en forma opuesta al Tribunal Constitucional, indicando que correspondía entregar la información requerida. Véase sentencia de Consejo para la Transparencia (Salmones Multiexport S.A.), Corte Suprema, rol I7.310-20I9, 4 de diciembre de 2019. 
ambiental y demás que resulten aplicables a la situación de contaminación de la mentada bahía" (el énfasis es nuestro).

El fallo también ordena un "plan de emergencia" a la Onemi; que se "reevalúe la calificación de zona de latencia y de zona saturada de las comunas de que se trata”; que se inicie un proceso de revisión de la resolución de calificación ambiental (RCA) de los proyectos o actividades en la zona "en conformidad al artículo 25 quinquies de la Ley 19.300"; y que la Seremi del Ministerio de Vivienda y Urbanismo aborde "la modificación del Plan Regulador de Valparaíso, en relación a la zona afectada a la brevedad, considerando dicha labor como una prioridad en sus políticas sectoriales".

De lo expuesto, se advierte que las acciones que la sentencia exige no tratan sobre una mera exhortación o consejo a la Presidencia de la República o a los servicios de su dependencia, sino del cumplimiento de un mandato específico. ¿Qué significado pueden tener exigencias de esta naturaleza? ¿Qué norma constitucional o legal autoriza a la Corte Suprema a dar este tipo de órdenes o emitir un juicio sobre la forma (más laxa o exigente) con la que se debe regular ambientalmente un contaminante o un gas? ¿Cuál sería el efecto si el presidente estima que no es conveniente "incrementar" los niveles de exigencia ambiental considerando otros factores, igual de legítimos, como la dimensión social o económica del área, haciendo efectivo el principio de desarrollo sustentable? ${ }_{2}$ Son vinculantes o imperativos estos mandatos de actuación?

Las preguntas formuladas no tienen respuesta en nuestro ordenamiento jurídico. En consecuencia, la Corte Suprema no debiese incursionar en un terreno cuya órbita está dentro de la función Ejecutiva, la que es, junto con la función Legislativa, la llamada a diseñar y ejecutar las políticas públicas, incluidas las ambientales. De su lectura, la sentencia no propone un diálogo cooperativo en la búsqueda de optimizar el ejercicio del derecho a vivir en un medioambiente libre de contaminación, sino más bien invadir materias propias del presidente de la República, ahondando en el mérito ("incrementando") y en la oportunidad ("a la brevedad”) con que deben modificarse normas o ejecutarse planes - más allá de lo deficientes, ineficientes y errados que sean-, lo que aumenta la incertidumbre respecto de lo que debe ejecutarse en la bahía de Quintero y Puchuncaví.

Así, el mandato de actuaciones que exige la sentencia no hace más que alterar el régimen de control que pesa sobre la Administración. De esta manera, por medio del recurso de protección, lo que termina haciendo la Corte Suprema es examinar el nivel de cumplimiento normativo de otro poder del Estado, pidiéndole, además, que regule y planifique políticas públicas, según propia visión regulatoria.

En este caso no se anula un acto administrativo o se condena a la Administración del Estado a pagar una suma de dinero, sino que se le pide actuar de una determinada manera en una zona específica, ejecutando una política pública bajo la particular visión de un poder del Estado, interpretando la propia sentencia cómo deben ser ejecutadas esas competencias. 
Sin perjuicio de lo anterior, no se trata de marginar la inactividad de la Administración del Estado del control judicial cuando existan obligaciones estatales concretas que desarrollar en razón de una norma, y que esa obligación genere derechos en un conjunto de personas (inactividad normativa) o que haya una tardanza excesiva en la dictación de una resolución (inactividad procedimental). Se trata de entender que el control sobre alternativas regulatorias (regular o no), bajo ciertas modalidades (estricta o flexible) y en base a ciertos y determinados componentes del medioambiente, está dentro de un margen de discrecionalidad o apreciación administrativa que debe ser respetado y que, en este caso, se ve interferido por la interposición de una acción cuya finalidad está reservada, en principio, para otro tipo de situaciones.

La sentencia razona, al imponer estas medidas, sobre todo las de naturaleza normativa, que solo existiría una respuesta correcta. Pareciera que la sentencia da "latigazos" ${ }^{17}$ al Poder Ejecutivo en función de órdenes regulatorias que no necesariamente son claras, completas, coherentes e inequívocas, y se olvida que el "el juez no puede configurar autoritativamente el orden jurídico general: solo puede librar decisiones para casos concretos; y en ello encuentra a su vez límites en el tenor de los textos normativos [...]. El principio de pasividad restringe adicionalmente la politicidad en esta dimensión, marcada por la dinámica de la iniciativa por estructurar el orden jurídico, económico y social”18.

Por todo lo anterior, esta sentencia parece confundir las políticas públicas que se impulsan o se priorizan y el cumplimiento de reglas que restringen día a día el quehacer de la Administración del Estado. Esto, porque aun cuando puede haber una política pública ambiental a lo largo de décadas que se considere errada, ineficiente y carente de justificación, ello es muy distinto de incumplir la Constitución, la ley y afectar un derecho constitucional por la ejecución deficiente de ella.

\subsection{La Corte Suprema confirma su rol como árbitro de la política ambiental}

En general, los jueces adquieren protagonismo cuando la política no resuelve problemas públicos complejos. Pero esa importancia adquiere mayor realce cada vez que, invocando derechos y principios, los tribunales de justicia los privilegian por sobre cualquier otra consideración de bienestar general.

17 Agustín Squella Narducci, "Independencia interna del Poder Judicial: Ante quiénes, en qué y para qué tenemos jueces independientes". En La Judicatura como organización (Santiago: Expansiva; Instituto de Estudios Judiciales, 2007), II-3I.

18 Eduardo Aldunate Lizana, "La independencia judicial: Aproximación teórica. Consagración constitucionalx y crítica”. Revista de Derecho de la Universidad Católica de Valparaíso i6 (I995): 23 . 
En materia ambiental, el derecho a vivir en un medioambiente libre de contaminación ha estado sujeto a una comprensión que ha ido variando en el tiempo. Desde el proyecto Trillium (1997) a Puchuncaví-Quintero (2019), la forma de comprender este derecho ha variado por parte de la Corte Suprema. No solo la Corte ha pasado desde una alta deferencia hacia la Administración (1997-2009) a un control intenso de expedientes recurriendo a los principios ambientales (preventivo y precautorio) para resolver diferentes asuntos complejos (2009-2014), sino que hoy, al menos en este caso particular, ha calificado y ordenado a la Administración, determinadas acciones de política pública regulatoria, buscando no solo resolver el caso concreto, sino además buscando una finalidad adicional, la que, por loable que sea, es injustificada, por lo que deben evitarse consideraciones instrumentales que desnaturalicen la finalidad del poder judicial, es decir, resolver el caso concreto con apego a las reglas sin buscar otros efectos adicionales. Como indica Fernando Atria, "el problema no es con el contenido de la finalidad, sino con el hecho de que el caso sea decidido teniendo presente una finalidad que no sea decidir el caso dando a cada uno lo suyo. La comprensión comisarial de la jurisdicción es radicalmente incompatible con la independencia judicial, y de ese modo hace improbable la jurisdicción, es decir: hace improbable que los individuos afectados sean tratados como fin, y no como medios" ${ }^{19}$.

La Corte Suprema, al igual que en otras materias, como el acceso a medicamentos de alto costo o en materia de empleo público, ha definido un rol en materia ambiental consistente en resguardar el derecho fundamental a vivir en un medioambiente de contaminación, olvidando, a veces, que todos los poderes del Estado pueden y deben deliberar en base a derechos fundamentales, todos con una contribución específica en el ejercicio pleno de esos derechos, por lo que no tienen los tribunales el monopolio de esa protección. En efecto, como bien plantean Yowell y Urbina, el ejercicio pleno de muchos derechos exige la creación de complejos esquemas institucionales, lo que requiere de legislación, con el Congreso como el lugar en que distintas visiones, de manera sistemática y estable, regulan un asunto ${ }^{20}$.

Pareciera, entonces, a partir de un tránsito que ha ido tomando tiempo, pero especialmente en este caso, que la Corte Suprema considera que los ciudadanos tendrían un título infinito para demandar al Estado de todo aquello que permita asegurar el ejercicio legítimo del derecho a vivir en un medioambiente libre de contaminación, desatendiendo las competencias de otro poder y cualquier otra ponderación que permita distribuir de manera equilibrada las competencias de cada uno, lo que deberá seguir siendo analizado para definir si esta tendencia se mantiene en el tiempo.

19 Fernando Atria Lemaitre, "La improbabilidad de la jurisdicción". En La judicatura como organización (Santiago: Expansiva; Instituto de Estudios Judiciales, 2007), 49.

20 Paul Yowell y Francisco Javier Urbina Molfino, "Derechos fundamentales y el problema de judicialización”, El Mercurio, 20 de septiembre de 20I8. En la misma línea, puede revisarse Gregoire Webber, Paul Yowell, Richard Ekins, Maris Kopcke, Bardley W. Miller y Francisco J. Urbina, Legislated Rights: Securing Human Rights through Legislation (Nueva York: Cambridge University Press, 20I8). 


\section{CONCLUSIONES}

La sentencia adoptada por la Corte Suprema respecto del caso Quintero-Puchuncaví tiene una relevancia que no se puede negar debido a las consecuencias institucionales que se derivan de ella. En particular, respecto de la forma de resolver el recurso de protección, que altera la naturaleza cautelar del mismo, y respecto del rol de la Corte Suprema en la política ambiental de nuestro país.

Por lo anterior, se ha estimado de interés el compartir estas conclusiones en torno al fallo de la Corte Suprema, toda vez que la forma de entender y aplicar varias instituciones en nuestro país, como la naturaleza del recurso de protección o el rol de la Corte Suprema, cobra mucha relevancia. Es posible notar también la tensión institucional que existe entre la Corte Suprema y el Tribunal Constitucional, así como también entre la Corte Suprema y la Administración del Estado, cuando materias referidas al medioambiente o la información afloran.

Por lo anterior, será importante hacer un seguimiento a futuras sentencias que dicte la Corte Suprema en materia ambiental, a fin de confirmar si se trata de una tendencia o si se trata de un caso aislado, producto de la excepcional situación que se vive en el sector de Quintero y Puchuncaví.

Por último, no dejamos de reconocer que buena parte de los comentarios que ilustran este trabajo también tienen como origen el diseño institucional del propio recurso de protección, el que, por la amplitud que le da su estructura, permite que pueda resolverse con mucha discreción por parte del tribunal, explicando, en parte, los problemas de la sentencia comentada. 


\section{BIBLIOGRAFÍA}

- Aldunate Lizana, Eduardo. "La independencia judicial: Aproximación teórica. Consagración constitucional y crítica”. Revista de Derecho de la Universidad Católica de Valparaíso 16 (1995). doi: 10.4151/ISSN.07186851-Vol.0-Num.16-Fulltext.295.

- Atria Lemaitre, Fernando. "La improbabilidad de la jurisdicción". En La judicatura como organización. Santiago: Expansiva, Instituto de Estudios Judiciales, 2007.

- Carrasco Quiroga, Edesio. "De Trillium a Central Los Cóndores: Continuidad y cambio del recurso de protección ambiental en veinte años de jurisprudencia”. Revista de Justicia Ambiental 9 (2017): 275-298.

- Peñalver i Cabré, Alexander. La defensa de los intereses colectivos en el contencioso-Administrativo. Santiago: Thomson Reuters Aranzadi, 2016.

- Squella Narducci, Agustín. "Independencia interna del Poder Judicial: Ante quiénes, en qué y para qué tenemos jueces independientes”. En La judicatura como organización. Santiago: Expansiva, Instituto de Estudios Judiciales, 2007.

- Webber, Gregoire, Paul Yowell, Richard Ekins, Maris Kopcke, Bardley W. Miller y Francisco J. Urbina. Legislated Rights: Securing Human Rights through Legislation. Nueva York: Cambridge University Press, 2018. 


\section{JURISPRUDENCIA CITADA}

- Confederación Nacional de Funcionarios con Tribunal Constitucional. Corte Suprema, rol 21027-2019, 7 de octubre de 2019.

- Consejo para la Transparencia (Salmones Multiexport S.A.). Corte Suprema, rol 17310-2019, 4 de diciembre de 2019.

- Francisco Chahuán Chahuán con Empresa Nacional de Petróleos, ENAP S.A. Corte de Apelaciones de Valparaíso, rol 7266-2019, 19 de febrero de 2019.

- Francisco Chahuán Chahuán con Empresa Nacional de Petróleos, ENAP S.A. Corte Suprema, rol 5888-2019, 28 de mayo de 2019.

- María Mónica Avilés González con Director General de Carabineros, Gustavo Adolfo González Jure. Corte Suprema, rol 2536-2013, 27 de junio de 2013.

- Municipalidad de Quintero con ENAP Refinería S.A. y Remolcadores Ultratug Limitada. Corte Suprema, rol 13.177-2018, 25 de septiembre de 2019.

- Sentencia del Tribunal Constitucional, rol 4986-18, 14 de mayo de 2019.

- Sentencia del Tribunal Constitucional, rol 2907-15, 27 de diciembre de 2016. 